\title{
MULTI-LAYERED DESIGN STRATEGIES TO ADOPT SMART DISTRICTS AS URBAN REGENERATION ENABLERS
}

\author{
J. GASPARI, S.O.M. BOULANGER \& E. ANTONINI \\ Department of Architecture, University of Bologna, Italy.
}

\begin{abstract}
Smart City emerged as a reference concept to shape the city of the future, mainly by strengthening the connections between grids, Information and Communication Technology (ICT) tools, governance and people. 'Smart' refers to the potential benefit that is derived by adopting ICT to face the increasing complexity of city growth, which involves multiple urban scales, a number of different players and a variety of regulatory frameworks, as shown by several experiences worldwide in the past few decades. Compared to the potential that is expected to be fuelled by hyper-connected devices in delivering an efficient and optimized configuration of the urban eco-system, the architecture of the city seems to have been relegated to the background. Facilitating an integrated management of the urban dynamics on both a large and a small scale is a key challenge. This means that the cross-related effects of decisions and behaviours must be identified, mapped and analysed considering their relations, reciprocal influences and conflicts. Although an effective ICT infrastructure should facilitate this purpose, the number of variables to consider is enormous, due to both top-down and bottom-up strains, which can act simultaneously on a large palette of fields, with multiple and combined issues as well. In order to design a model on which a tool for management can be built, a simplified scale of analysis is needed: the 'district' seems to represent an acceptable intermediate portion of the whole city where local and global phenomena can be observed from a perspective of their interferences and potential synergies. It often also corresponds to an administrative entity as well as to a structured place recognized by citizens and inhabitants. This article reports on a study conducted in the city of Bologna by a team of researchers of the University of Bologna - Department of Architecture. The study aimed at supporting the municipality in defining effective strategies to implement the Smart City Vision by a set of coordinated actions of regeneration at district level. The research aimed at coupling holistic design principles and the typical ICT platform architecture into an inter-operable tool that could enable the management of the key features of a district in separate layers, supplemented by different data sets. A significant part of the research has been devoted to identifying the variables involved and defining the methodology to process them, according to the most up-to-date shared definitions and indicators.
\end{abstract}

Keywords: built environment, energy efficiency, multi-layer design, smart city, smart district, urban regeneration.

\section{INTRODUCTION}

In the recent past, the Smart City (SC) concept has emerged as a possible answer to worldrelevant challenges most metropolitan cities are facing at different levels [1, 2]: massive urbanization, increase of demographic pressure due to migration flows, $\mathrm{CO}_{2}$ emissions and economic and social constraints as never before [3-9]. As pointed out by several studies $[1,3,10,11]$, the smart city paradigm and the extended use of ICT tools are often adopted to facilitate coordinated and more sustainable actions [3,5]. Despite the rapid progress achieved in this field, a shared and common definition of an SC is still missing [5, 12-16]. This prevents a clear understanding of the potential hidden behind the supporting tools to foster the transition process and to coherently create effective synergies when adopting smart building and smart city solutions to shape the architectural landscape of the future.

The article aims to identify some recurring key concepts/themes describing the SC notion in scientific literature and in recent/ongoing research projects. This provides a reference to 
define the main layers of a multi-criteria platform to be used for supporting the application of ICT tools in the design process of effective actions, especially on a district scale assumed as an intermediate scale where urban transformation and transition processes are usually carried out. The article reports on the results of a study developed by the Technology Research Team of the Department of Architecture at the University of Bologna aimed at supporting the Bologna Municipality in defining effective strategies at the district level, by performing separate but coordinated regeneration actions within the framework of the general Smart City Vision [17]. Although the district, as a pilot dimension for testing solutions, has been widely discussed $[18,19]$ including several potential features (geographical, social, administrative, functional) that are suitable to define it, the research assumed the district as an intermediate urban dimension that is recognizable to its citizens [19]; having a minimum physical dimension for implementing projects; having a relevance compared to the whole city and being mainly devoted to a specific function (e.g. residential, commercial, etc.). A considerable portion of the research has been devoted to delivering a state of the art - which is reported in the first part of the article - in which a comprehensive perspective of the key concept definitions has been provided, aiming at bridging the gap between their meaning and understanding. On this basis, a methodology has been developed to assess the level of 'smartness' that may characterize an urban situation and its potential improvement by specific regeneration actions assumed as tools to revitalize the spatial, social and economical dimensions of the site [20].

Since the research aims to couple the holistic design principles and the typical ICT platform architecture into an interoperable tool, the key district features have been referred to separate layers, fed by different data sets in order to facilitate the management of the complex interaction given by the wide range of variables involved in the process.

\section{BACKGROUND AND ASSUMPTIONS}

\subsection{General framework}

To support the fulfilment of EU directives 31/2010 (Directive 2010/31/EU of the European Parliament and of the Council of 19 May 2010 on the energy performance of buildings) and 27/2012 (Directive 2012/27/EU of the European Parliament and of the Council of 25 October 2012 on energy efficiency) the city developed and adopted the Bologna Adaptation Plan in 2015 [21]. A number of ICT-based solutions were implemented accordingly in order to achieve the Bologna Smart City Vision. Thus, the first step in the research was to obtain a clear definition of the smart city concept $[14,16,22]$.

The debate on the notion of 'smart' dates back to the late 1980s and early 1990s with the advent of the information age. On the one hand, it was the integration of ICT-based tools to trigger the idea and on the other defining the concept of useful, simple and cheap methods associated with the term smart [5]. According to Nam and Pardo [14], it seems to be generally accepted that the aim of smart growth is to combine economic and social issues with sustainable urban development, by a process where ICT plays the key role of enabler. Then, the smart city topic's strong bond with technology started to be more and more coupled with sustainability issues, $[3,23]$ especially dealing with climatic and social challenges [2]. Some research [1, 24-27] highlights these aspects, pointing out the importance of cross-cutting strategies to meet the present urban challenges [28]. Facing the multiple dimensions of the topic, a literature and research screening appears to be a suitable reference to establish a set of assumptions and definitions that reflect coherent and shared positions. 


\subsection{State of art review}

The state-of-art review was set up to screen research on smart cities, focusing on those that assumed environmental issues and climate change responsive strategies as key elements, which were clearly addressed as a priority by the Municipality of Bologna. A systematic review [29] has been performed on Google Scholar,-and on Cordis, the web portal where EU-funded projects are collected by adopting a methodology coherent to Cooper taxonomy (see Table 1) [30].

The Google Scholar search included all kinds of documents (reports, theoretical analysis, methodologies, research outcomes, scientific papers) in a time range between 2000 and 2015 when the smart city concept was spreading. Data from the 1990s was complemented by a recent study [31] retrospectively analysing the topic literature in that period. Within the time frame defined, the references were retrieved from the Goggle Scholar database by the following set of keywords: smart district; smart building AND indicator; smart city AND indicator AND sustainable; smart building AND refurbishment; urban regeneration AND smart city AND sustainable; smart city AND retrofitting OR renovation OR refurbishment. The listed combinations produced 4,423 results, 490 of which were selected based on the relevance assigned to the document and excluding the following: documents containing citations only; patents; slide show presentations; documents not written in English or Italian; papers focusing on specific engineering topics (i.e. heating systems, grids, etc.); papers concerning only tourist or artistic/historical or cultural heritage issues. The findings were firstly ranked in chronological order, to map their relevance in the evolution of the topic and considering the most updated trends and, secondly, in conceptual order according to the research scope.

Table 1: Cooper taxonomy applied to smart district literature review.

\begin{tabular}{|c|c|c|}
\hline Characteristics & Cooper's option & Adopted selection criteria \\
\hline Focus & Typologies of papers involved & $\begin{array}{l}\text { All papers involved: theoretical, } \\
\text { conceptual, methodological, case } \\
\text { study }\end{array}$ \\
\hline Goal & $\begin{array}{l}\text { Integration (e.g. bridge the gap } \\
\text { between theories, etc). } \\
\text { Criticism (e.g. demonstrate a theory) } \\
\text { Central issue }\end{array}$ & $\begin{array}{l}\text { Central issue. Coherent to the } \\
\text { literature review scope }\end{array}$ \\
\hline Organization & $\begin{array}{l}\text { Data mining: chronological, } \\
\text { conceptual, methodological }\end{array}$ & $\begin{array}{l}\text { The data mining is developed with } \\
\text { chronological and conceptual } \\
\text { organization }\end{array}$ \\
\hline Perspective & $\begin{array}{l}\text { Neutral position, espousal of a } \\
\text { position }\end{array}$ & Neutral position \\
\hline Audience & Target of the literature review & $\begin{array}{l}\text { The audience is specialized } \\
\text { researchers, policy makers, } \\
\text { architects acting on urban context }\end{array}$ \\
\hline Coverage & $\begin{array}{l}\text { Exhaustive, exhaustive with } \\
\text { selective citations, representative, } \\
\text { central, pivotal }\end{array}$ & Representative \\
\hline
\end{tabular}


Time evolution of the concept - The selected references were classified according to publication date so as to analyse the emerging trends and to demonstrate that the linkage between smart city and district regeneration is quite recent. Until 2010, the topic was covered by only a few articles and papers, while a remarkable increase in publications is recorded since 2010. This can be explained by an increased demand from the EU and national regulations application. Figures 1 and 2 show the increase of relevance of papers connecting smart city and district regeneration year by year.

Thematic interpretation - According to key words listed in each document and the recurrence of the string combinations in the main text, the results were assigned to 9 main categories: 1) case studies (reporting the outcomes of application in real contexts); 2) economy and policies (i.e. stakeholder engagement, guidelines, business models, etc.); 3) ICT/ technology (analysing the role in process implementation); 4) performance and indicators (descriptions of the main parameters and related derived indicators); 5) methodologies and models (describing analytical structure, design options, implementation models); 6) social involvement (i.e. creative districts, living labs, etc.); 7) theories (describing theoretical and position approaches, i.e. terms and concepts definitions, interpretation of trends, etc.); 8) low carbon transition (describing transition, adaptation, regeneration processes); 9) cousin words (including similar or related concepts, i.e. intelligent city, eco-city, digital city). Theoretical approaches are predominant, followed by methodologies and case studies. The prevalence of theory can be taken as evidence of the need for defining the boundaries of the topic and its key features.

The relevance of case studies demonstrates the need for testing the assumption in real conditions, however this can vary significantly from place to place. The large number of pilot applications is not mutually fed by each other's experiences thus reflecting the lack of a systematic development in the field due both to the early stage and the complexity of the issue.

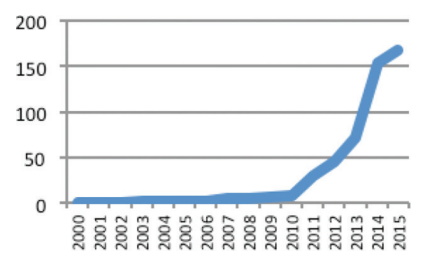

Figure 1: Time analysis of Smart City. and District refurbishment, $\mathrm{n}^{\circ}$ of elements.

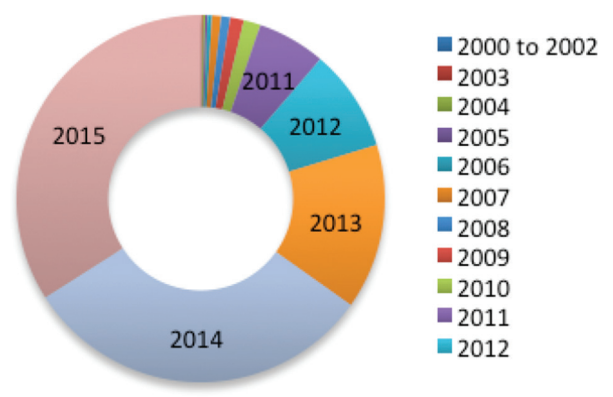

Figure 2: Time analysis of Smart City and District Refurbishment, percentage. 
The share by topic is displayed in Figure 3. The analysis shows that smartness seems to have two main cores: the technological component, which includes both hard infrastructure (the enabling systems and devices: IT, web-based) and software infrastructure), combined with ecological/sustainable features. The transition towards low- carbon cities involves economic and social growth as well as the inclusion of communities [32-34].

Document typology interpretation - The selected documents were then classified according to their typology (see Figure 4): books; book chapters; EU documents (official documents, issued by EU Institutions and governmental or official bodies); EU projects; scientific papers; theses (master or doctoral). The predominant typology is the scientific paper reflecting the need to establish a consolidated background on the topic. However, some common outcomes emerged. Urban development through transition towards low-carbon sustainable districts is a growing research topic that is closely connected to smart city issues.

The Cordis portal was searched according to the following keywords: 'smart city' AND district OR retrofitting OR renovation OR regeneration OR urban; 'smart city'. The following filters were applied: research on 7th work programme AND research on H2020 work programme; research only in PROJECTS. 25 projects, were found and further filtered according to the following criteria: exclusion of projects not applied to urban or district contexts; exclusion of projects with educational purposes; exclusion of duplicated results. The outcomes were double checked with the 'Smart City Platform' database as an additional source. All the selected projects have a complex structure that was examined as a starting point for the Bologna case study and to define the multi-layer architecture of the design tool object of the study.

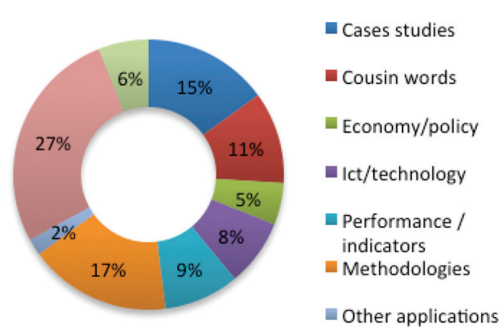

Figure 3: Thematic analysis $\%$.

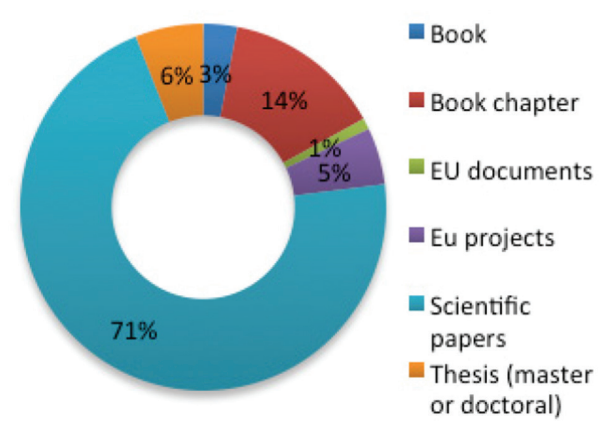

Figure 4: Product typology \%. 


\section{METHODOLOGY AND DEFINITIONS}

\subsection{Applied methodology}

The massive amount of information screened and the variations in terminology and meaning among themes belonging to the same category made it necessary to accept a certain level of approximation in creating some main families in order to progress further with the research.

The key objective was to support the replacement of the conventional approach to renovation of the existing stock which - being usually aimed at achieving pre-defined performance thresholds for each single building according to specific energy savings targets - assumes city regeneration processes as the collection of these single results [25, 35] and moves towards a more coordinated vision that adopts ICT tools and smart principles as the key enabler [36]. The core idea of the project is therefore to couple the holistic vision with ICT architecture in order to include in the interoperable platform a number of 'layers' representing the key themes and concepts on which the smart and sustainable city vision can be linked as shown in Fig. 5. The main problem that arose was the complexity generated by managing the whole process on a city scale and the lack of adequate connections while working on the scale of a building. Therefore, the very first task of the project was to structure the whole platform as a scalable tool and to fix its key element at the district scale. The complex interaction of variables and specific conditions, typically characterizing the dense urban environment, requires the separation of both data flows and their representation in order to provide a simplified tool to visualize possible conflicts or synergies and facilitate the understanding of phenomena for a different range of players (who are mostly non- expert users). The core idea of the research is to aggregate variables and data belonging to the same domain into a number of key layers organized into sub-categories that make it easier to filter information and browse the data-sets in separate or aggregated visualizations.

The methodology was developed as follows:

- sub-categories identification by analysing the recurrence in the screened projects and their definition accordingly;

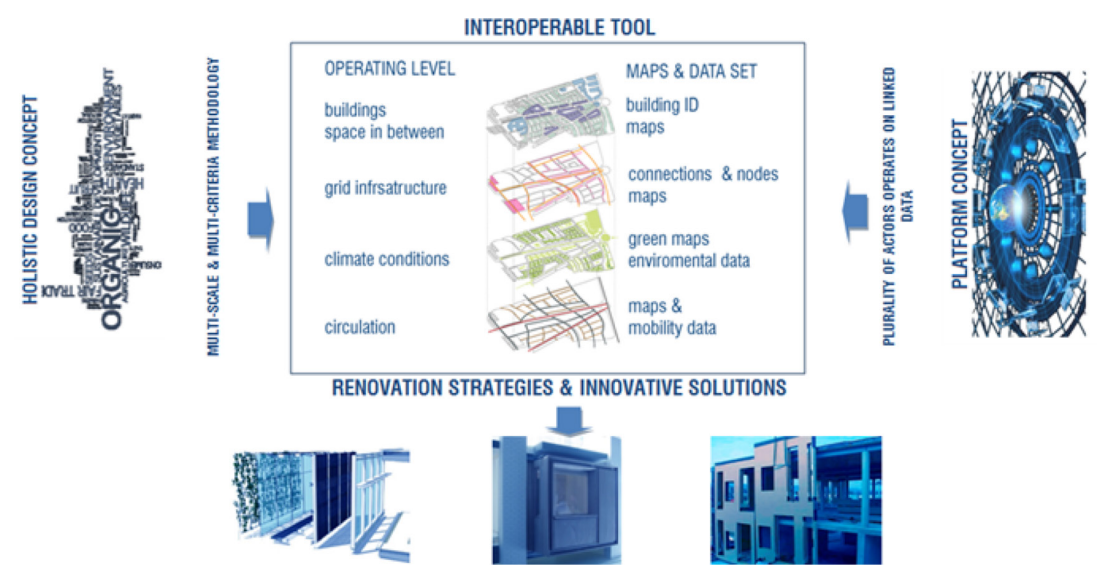

Figure 5: The core idea is based on a multi-layer structure that aims to facilitate the management of interactions and optimize the design solutions. 
- application of indicators to the parameters involved, to be used to feed graphic maps representing the related data sets;

- aggregation of sub-categories into key layers, to be used to display data on graphic maps for facilitating end-user visualization of results;

- definition of the platform architecture as a whole

- test on a demo-case and check of replicability potential.

\subsection{Definition of the thematic layers}

The very first problem of this approach was how to define the layers so that they could be general enough to be applied to different contexts but specific enough to adequately describe a consistent part of urban phenomena. The outcomes of the state-of-the-art review, and especially those coming from the project screening, were used to support the layer definition phase. Each source was investigated to select the categories used to describe the main issues in a smart and sustainable city perspective and definitively select the most used and recurrent thematic group so as to adopt shared definitions understandable to a wide range of potential users [24-27, 37].

Based on the different realms (mobility, energy grids, people, communication, etc.) [38] and according to the outcomes of the performed review results (recurrency of the theme in the concept definition) 5 main 'layers' were identified: circulation, which is closely connected to smart mobility and the physical infrastructure at the city and district level, where the smart district can be defined as an urban geographical, socio-economic unit that can be associated with a specific culture and identity [39]; climate conditions, which includes all the variables dealing with the specific characteristics of the environment (such as temperature, humidity, wind speed, rainfall, etc.); buildings, which represent the single units of the built environment and are assumed to host the ICT supported backbone controlling sensors, actuators, micro-chips, micro/nano-embedded systems used to manage the key functionalities while collecting and filtering information locally with the purpose of managing aggregated data at city level according to business functions and services [40]; space in-between, which represents the connective fabric where most interactions take place; grids infrastructure, which typically refers to services and systems associated with the so-called smart grids. Each key layer includes a number of sub-categories in order to optimize the description of the combination between the variables and the deriving phenomena. All these definitions and key layers were used to define the platform architecture and structure with the aim of managing separate data put into aggregated visualization output in order to facilitate the understanding of the potential related to alternative renovation scenarios.

\subsection{Platform structure}

From a methodological point of view, the layered architecture of data is the backbone of the platform while the sub-categories are assumed as a set of homogeneous information.

The platform conceptual structure is designed to be implemented with new additional layers in case the complexity of phenomena requires them. Furthermore, this responds both to the need to use existing and already available data sets and new ones whose data can be specifically collected according to new purposes. The resulting structure is displayed in Fig. 6. Each key layer aggregates information concerning the sub-categories that are fed by the 


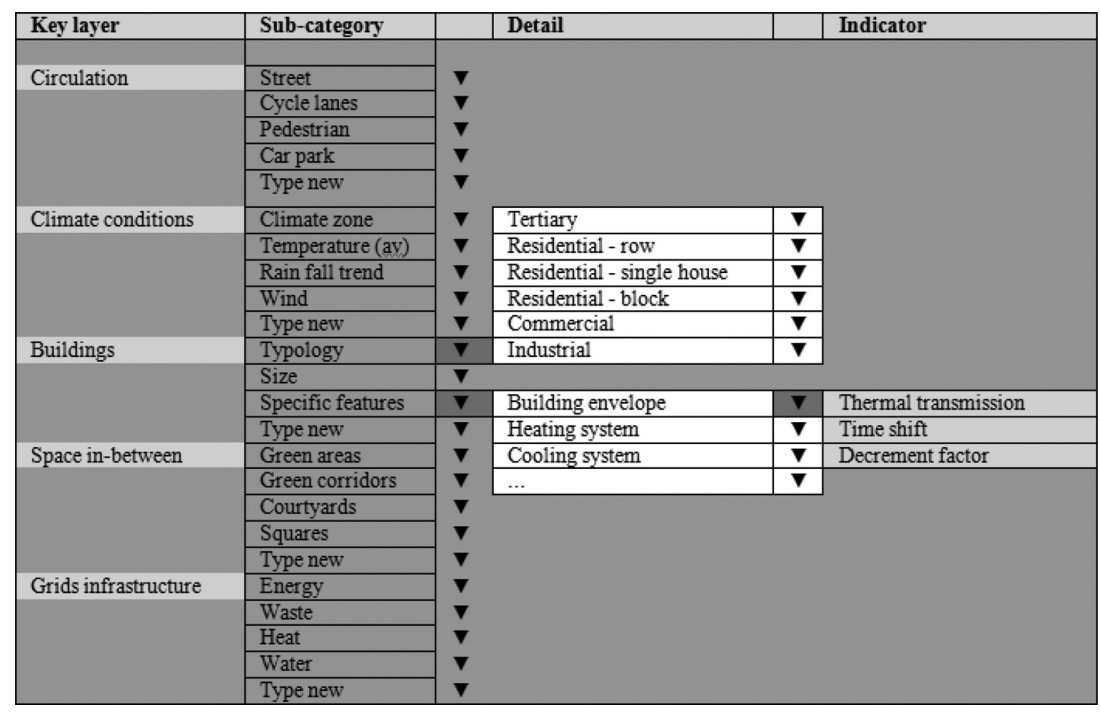

Figure 6: architecture of the tool with the key layers and sub-categories.

existing database or by monitoring tools already installed or to be installed in the buildings and/or in the service infrastructures. When a sub-category is filled, specific descriptors are adopted and adequate indicators are assumed accordingly. Thus, the process works in two directions, one for feeding each data set and the other for putting questions to the system using a sub-category as a filter.

An easy example of how the structure works is offered by a very common goal of regeneration processes concerning the reduction of energy demand for cooling and heating.

With the aim of defining effective solutions, the key parameters are usually displayed in a number of data sheets, like the one shown in Fig. 7, and can be represented by a map at the district level visualizing homogeneous conditions according to the selected indicators.

This can be applied to each sub-category and layer providing a facilitated access to information as well as an easy way to compare interrelated data sets. A map of the green areas can be easily associated with a map of air temperature (which is described by isolines) or of ventilation (see Fig. 8) to analyse the potential influence of green surface remodelling in the same zone with mitigation purposes. In this sense, the test phase on the demo-site was useful for studying possible interaction topics to be further developed at a future stage of the research. This is just one example of correlation processes, others can deal with circulation and mobility data, thermal behaviour of building envelopes and demand data from energy suppliers, etc. The key layers can be implemented according to needs; however, for functional reasons the easiest way to implement the tool is to add new sub-categories with related details.

The platform is expected to be integrated with already existing ICT tools and software in order to ensure the widest compatibility and to ease data collection. The tool is intended for important data gathering and analysis, to include GIS-based (geographic information system) maps and to allow smart simulations for providing fast feedback after any changes to the parameter settings. 


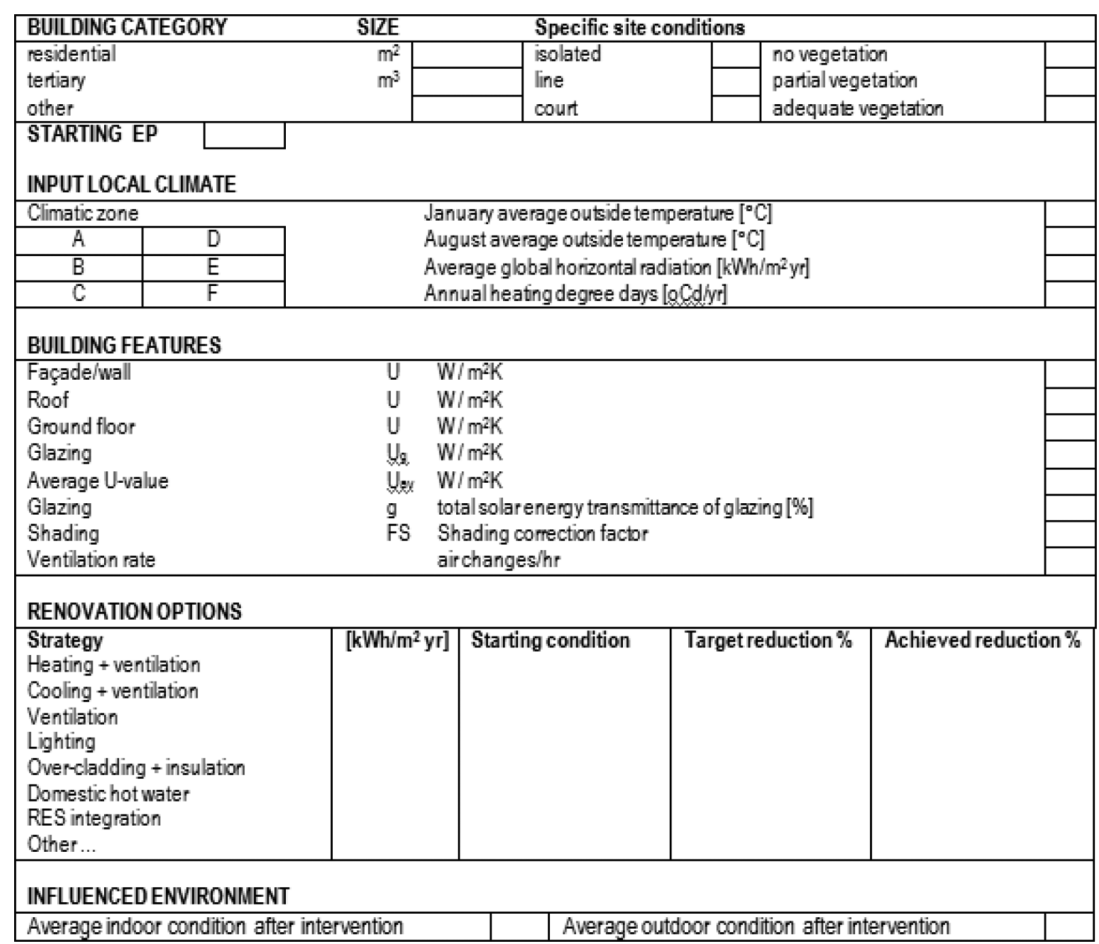

Figure 7: architecture of the tool with the key layers and sub-categories.
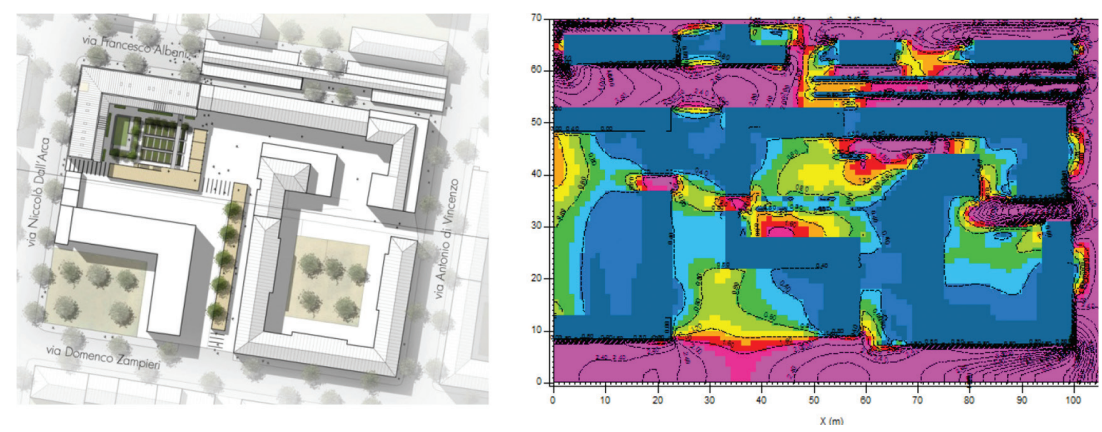

Figure 8: example of wind map (b) compared with green re-design (a) of a portion of the urban fabric on the demo-site.

\section{RESULTS, IMPACTS AND REPLICATION POTENTIAL}

The main results of the study deal with two different levels: on the one hand, the attempt to define thematic layers that represent the recurrent issues detected in the performed review in order to have a broad range of categories included in an easier structure to manage; on the other hand, the architecture assigned both to the methodological backbone and to the platform itself represents a promising field of work in boosting synergies and connections 
between initiatives and solutions. The original character of the research lies in considering the district meso-scale in terms of renovation projection, performance level, achieved results, while analysing and processing data acquired on the single elements (buildings, green areas, circulation, etc.) composing it. This approach requires a very multi-disciplinary team including experts from different domains particularly regarding ICT development and software integration.

The research is expected to have a positive impact on the city regeneration process. In the short term, it will drive innovations in energy management and control technologies in the renovation market - which is the widest field of application from the Municipality's point of view in several areas of the City - and will increase the key player awareness thus generating a greater demand for both innovative, retrofit solutions (e.g. insulation, ventilation, water saving, etc.) and training and support services for building managers [37, 41]. In the medium term, although it might be randomly replicated in different sectors of the city according to the dotted nature of investments and to the emerging needs, it will direct the processes into a coordinated vision drafted following the pattern designed by the thematic maps of each layer like pieces of a single mosaic. The main barrier to speeding up the process is the lack of resources available to plan interventions in the long-term perspective that usually lead to single isolated initiatives rather than to larger portions of the city. The ownership regime is also a critical element that hinders coordinated decision-making processes. However, the very active cooperation with the Municipality of Bologna is a promising premise in order to successfully overcome procedural and contextual barriers and to boost tool adoption and use by the key players involved.

\section{CONCLUSIONS AND DISCUSSION}

This multi-perspective approach is a response to what the City of Bologna, as problem owner, profiled when asked to facilitate the cooperation between all subjects - from suppliers to citizens and communities - in order to optimize energy efficiency measures, find adaptable solutions and increase the overall quality at district level according to a coordinated vision [37, 42-44]. The envisaged methodology requires a constant updating of the key parameters (i.e. building features concerning both the construction system and equipment, site features, relation with neighbouring buildings, circulation, connection to grids, etc.) as well as the protocols for data acquisition. A circular check process is used to assess the effect each technical solution to be implemented may produce according to pre-defined targets of performance and quality. The platform is therefore the first application of the methodology and, at the same time, the tool to check its coherence and reliability. The next steps will be the implementation of the demo-cases and the related extension of platform functionalities according to the envisaged multi-user perspective. The ambitious character of the research requires several intermediate evaluations to allow the development of each single phase according to a circular checking process. In addition, each single stage is planned separately according to budget availability so as to ensure the advance of the research.

The originality of the research is indeed mostly connected with its multi-criteria and multiuser dimension, which are closely connected to the core concept of scalability that was assumed in the very early phase of the project conception as the key element to satisfy the replicability of the methodology either in several parts of the city or in other cities with different contexts and size. This represents a crucial element for defining adequate pathways to replicate the process elsewhere and for driving the platform structure to further implementations - not simply referred to the potential additional layers, but mostly to new potential 
applications dealing with the smart dimension, which will require a constant exchange of information between the real and the virtual realm in shaping the cities of the future [45].

\section{REFERENCES}

[1] R. P. European Union, Cities of tomorrow. Challenges, visions, ways forward, 2011, available at http://ec.europa.eu/regional_policy/sources/docgener/studies/pdf/ citiesoftomorrow/citiesoftomorrow_final.pdf

[2] EIP on Smart Cities and Communities, "Strategic Implementation Plan”, 2013.

[3] Hajer, M. \& Dassen, T., Visualizing the Challenge for 21 st Century Urbanism, Amsterdam, 2014.

[4] Secchi, B., La città dei ricchi e la città dei poveri, Laterza, 2013.

[5] Bonomi, A. \& Masiero, R., Dalla Smart City alla Smart Land, Marsilio, 2014.

[6] Pickett, A.T.A., Boone, C.G., McGrath, B.P., Cadenasso, M.L., Childers, D.L., Ogden, L.A., McHale, M. \& Grove, J.M., Ecological science and transformation to the sustainable city. Cities, 32, pp. S10-S20, 2013.

https://doi.org/10.1016/j.cities.2013.02.008

[7] The World Bank, "Cities and Climate change: an urgent agenda", 2010, available at http://siteresources.worldbank.org/INTUWM/Resources/340232-1205330656272/ CitiesandClimateChange.pdf

[8] Ferrao, P. \& Fernandex, J.E., Sustainable urban metabolism. The MIT Press, p. 264, 2013.

[9] European Environment Agency, "Urban adaptation to climate change in Europe", 2012, available at http://www.eea.europa.eu/publications/urban-adaptation-to-climatechange.

[10] Engelke, P., Foreign Policy for an Urban World: Global Governance and the Rise of Cit ies, 2015, available athttps://www.ciaonet.org/attachments/28077/uploads?1446493739

[11] Espon, Territorial Dimensions of the Europe 2020 Strategy, 2013.

[12] Batty, M., The future cities agenda. Environmental Planning B Planning and Design, 40, pp. 191-194, 2013. https://doi.org/10.1068/b4002ed

[13] Hall, R.E., Bowerman, B., Braverman, J., Taylor, J. \& Todosow, H., The vision of a smart city. In 2nd International Life Extension Techology Workshop, 2000, available at http://www.osti.gov/scitech/servlets/purl/773961

[14] Nam, T. \& Pardo, T.A., Conceptualizing smart city with dimensions of technology, people, and institutions. Proceeding 12th Annual International Digital Goverment Research Conference Digital Government Innovation in Challenging Times, pp. 282-291, 2011. https://doi.org/10.1145/2037556.2037602

[15] Roche, S., Nabian, N., Kloeckl, K. \& Ratti, C., Are 'smart cities' smart enough? GSDI World Conference, pp. 215-236, 2012.

[16] Wolfram, M., Deconstructing smart cities: an intertextual reading of concepts and practices for integrated urban and ICT development. Real Corp, pp. 171-181, 2012, ISBN 978-3-9503110-2-0

[17] Antonini, E., Gaspari, J. \& Boulanger, S.O.M., Multi-layered urban strategies to foster the smart cities development. The Sustainable City X, WIT Press, 194, pp. 23-34, 2015, ISSN 1743-3541 
[18] Balducci, A. e Fedeli, V., Quartieri che cambiano In Territori della città in trasformazione. Tattiche e percorsi di ricerca, Angeli, Milano, 2007.

[19] Barton, H. (eds), Sustainable Communities: The Potential of Eco-Neighbourhood, Eartschan, London, 2000.

[20] Foerlev, B., Urban regeneration — a role for research? Batiment International. Building Research and Practice, 10(2), 1982.

[21] Municipality of Bologna, BLUE AP. Bologna Local Urban Environment Adaptation Plan for a Resilient City, available at http://www.blueap.eu/site/.

[22] Neirotti, P., De Marco, A., Cagliano, A.C., Mangano, G. \& Scorrano, F., Current trends in smart city initiatives: Some stylised facts. Cities, 38, pp. 25-36, 2014. https://doi.org/10.1016/j.cities.2013.12.010

[23] Williams, K., Burton, E. \& Jenks, M., Achieving Sustainable Urban Form, E \& FN Spoon, London, 2000.

[24] Hajer, M. \& Dassen, T., Visualizing the Challenge for 21st Century Urbanism, Ed. naio10publisher/PBL publishers, Amsterdam, 2014.

[25] GIZ and ICLEI, Operationalizing the Urban NEXUS. Towards resource-efficient and integrated cities and metropolitan regions, 2014, available at http://www2.giz.de/ wbf/4tDx9kw63gma/UrbanNEXUS_Publication_ICLEI-GIZ_2014_kl.pdf

[26] Floater, G. \& Rode, P., Cities and the New Climate Economy: The transformative role of global urban growth, 2014, available at https://files.lsecities.net/files/2014/11/LSECities-2014-The-Transformative-Role-of-Global-Urban-Growth-NCE-Paper-01.pdf

[27] European Commission Directorate General, LIFE and Climate change adaptation, 2015.

[28] Mattoni, B., Gugliermetti, F. \& Bisegna, F., A multilevel method to assess and design the renovation and integration of smart cities. Sustainable Cities and Society, 15, pp. 105-119, 2015.

https://doi.org/10.1016/j.scs.2014.12.002

[29] Vom Brocke, J., Simons, A., Niehaves, B., Riemer, K., Plattfaut, R. \& Cleven, A., Reconstructing the giant: on the importance of rigour in documenting the literature search process. ECIS 17th European Conference on Information Systems, pp. 2-13, 2009.

[30] Cooper, H.M., Organizing knowledge synthese: a taxonomy of literature review. Knowledge in Society, 1, pp. 104-126, 1988.

https://doi.org/10.1007/BF03177550

[31] Cocchia, A., Smart and digital city: a systematic literature review, in smart city. In Smart City, eds R.P. Dameri \& C. Rosenthal-Sabroux, Springer International Publishing: Switzerland, p. 32, 2014.

[32] OECD, Handbook on Constructing Composite Indicators: Methodology and User Guide, 2008, available at https://www.oecd.org/std/42495745.pdf

[33] United Nations, Indicators of Sustainable Development: Guidelines and Methodologies, Economics and Social Affairs, 3rd ed., pp. 1-90, 2007, available at http://www. un.org/esa/sustdev/natlinfo/indicators/guidelines.pdf

[34] Directorate-General for internal policies- European Parliament, Mapping Smart Cities in the EU, 2014, available at http://www.europarl.europa.eu/RegData/etudes/etudes/ join/2014/507480/IPOL-ITRE_ET\%282014\%29507480_EN.pdf

[35] Stafford, A., Gorse, C. \& Shao, L., The Retrofit Challenge: Delivering Low Carbon Buildings, Centre for Low Carbon Futures: Leeds, UK, 2011. 
[36] Abastante, F., Lami, I.M., Lombardi, P. \& Toniolo, J., Towards Sustainable Urban district: a MACBETH approach. In: Towards Post Carbon Cities, Torino, pp. 134-143, 2016.

[37] Giffinger, R., Hemis, H., Weninger, K. \& Haindlmaier, G., PLEEC. Planning for energy efficient cities. Methodology for Monitoring, 2014, available at http://www. pleecproject.eu/downloads/Reports/Work\%20Package\%202/wp2_d24_methodolgy_ for_monitoring.pdf

[38] ISO/IEC JTC 1 Information Technology, Smart Cities. Preliminary Report, 2014, available at http://www.iso.org/iso/smart_cities_report-jtc1.pdf

[39] Jiménez, J.P., Martìn, A., Rosa, P.D.L., Aguilera, O. \& Pulido, E.P., DAREED. Definition of a methodology for district modelling, FP7 project "DAREED", 2014, available at http://www.dareed.eu/-/m/124/DAREED\%20Project\%20-\%20WP1\%20-\%20D1.4.pdf

[40] European Commission - Directorate General Information Society and Media - ICT for Sustainable Growth Unit, "Smart Buildings", 2009, available at http://ec.europa.eu/ information_society/activities/sustainable_growth/docs/sb_publications/smartbuildings-ld.pdf

[41] Fertner, C., Groth, N.B., Grosse, J., Read, S. \& Rocco, R., Framework for reports on urban energy planning in 6 case cities, 2014.

[42] Giffinger, R., Fertner, C., City ranking of European Medium-Sized Cities, Vienna University of Technology, University of Ljubljana, Delft University of Technology, 2007.

[43] Un Habitat, State of The World's Cities 2012/2013: Prosperity of Cities, Routledge: New York, NY, USA, 2013.

[44] Erell, E., Pearlmutter, D. \& Williamson, T., Urban Microclimate: Designing the Spaces Between Buildings, Earthscan: London, Washington, DC, p. 266, 2011.

[45] Smart City Council, Smart Cities Readiness Guide: The planning manual for building tomorrow's cities today, 2013. 